Gut, 1972, 13, 124-127

\title{
Intraabdominal abscesses due to azathioprine for Crohn's disease
}

\author{
T. C. NORTHFIELD AND C. I. ROBERTS ${ }^{1}$ \\ From the Department of Medicine, Guy's Hospital, London
}

SUMMARY We report here a case of Crohn's disease in which there is strong circumstantial evidence that azathioprine precipitated the development of an intraabdominal abscess on two separate occasions. On both occasions, the abscess developed within a few weeks of the patient starting azathioprine, and complete healing occurred on stopping azathioprine. The patient had never previously had this complication. On both occasions, the only early indications of a developing infection were the appearance of toxic granulation of neutrophils in the peripheral blood and a progressively rising erythrocyte sedimentation rate.

Encouraging results have been reported for the treatment of Crohn's disease with azathioprine (Brooke, Hoffmann, and Swarbrick, 1969; Brooke, Javett, and Davison, 1970; Jones, Brown, LennardJones, Jones, and Milton-Thompson, 1969). It might be anticipated that immunosuppression would carry a special risk of infective complications in a disease in which the presence of intraabdominal sepsis is a characteristic feature. One of the patients described by Brooke et al (1970) developed a septicaemia while on azathioprine, but this might have been coincidental.

\section{Case Report}

A 17-year-old boy was admitted to Guy's Hospital in December 1966 with a history of colicky upper abdominal pain for one year; of weight loss amounting to $10 \mathrm{~kg}$ in six months; and of diarrhoea for two months, with passage of two to three fluid motions daily. He had a fever of up to $38^{\circ} \mathrm{C}$, and on examination he had a tender mass in the right iliac fossa. Sigmoidoscopy was normal, but barium studies showed an abnormal terminal ileum, with cobblestone appearance, and a segmental lesion affecting the proximal half of the transverse colon. Laparotomy revealed the classical appearances of Crohn's disease involving the terminal ileum, the caecum, the proximal half of the transverse colon, and a small segment of the descending colon. Neither resection nor biopsy were carried out. The patient

${ }^{1}$ Please address requests for reprints to Dr C. I. Roberts at above address.

Received for publication 25 November 1971. was started on prednisolone $30 \mathrm{mg}$ daily, with good symptomatic improvement, and was discharged from the hospital.

The dose of steroids was gradually reduced, and in May 1967 they were stopped altogether. He then remained well till March 1968 when he had a recurrence of symptoms which again improved on steroids. He has remained on steroids ever since, apart from a three-month period from September 1968.

On 11 October 1969, he was readmitted with a recurrence of all his original symptoms in the previous five months. He weighed $42 \mathrm{~kg}-\mathrm{a}$ loss of $10 \mathrm{~kg}$ during this period. He was taking prednisolone $10 \mathrm{mg}$ daily and the dose was not changed at any stage during this admission. He again had a fever of up to $38 \cdot 3^{\circ} \mathrm{C}$. He had no abdominal masses or tenderness. Barium studies on this occasion showed a fistula between the ileum and the sigmoid colon, and two separate segmental lesions in the descending colon, in addition to the changes noted previously. The lesion in the transverse colon now showed the characteristic 'spiking' appearance of Crohn's disease. On 17 October the patient was started on azathioprine $150 \mathrm{mg}$ daily. The subsequent clinical course is recorded in Figure 1. On 28 October toxic granulation of neutrophils was noted for the first time on his blood film. On 3 November the total white cell count had fallen to 3500 cells $/ \mathrm{cmm}$. Azathioprine was therefore discontinued. It was restarted on 7 November at a reduced dose of $100 \mathrm{mg}$ daily, being increased again on 3 December to 150 $\mathrm{mg}$ daily. On 8 December, he developed pain in the left loin, which spread to the left thigh on December 


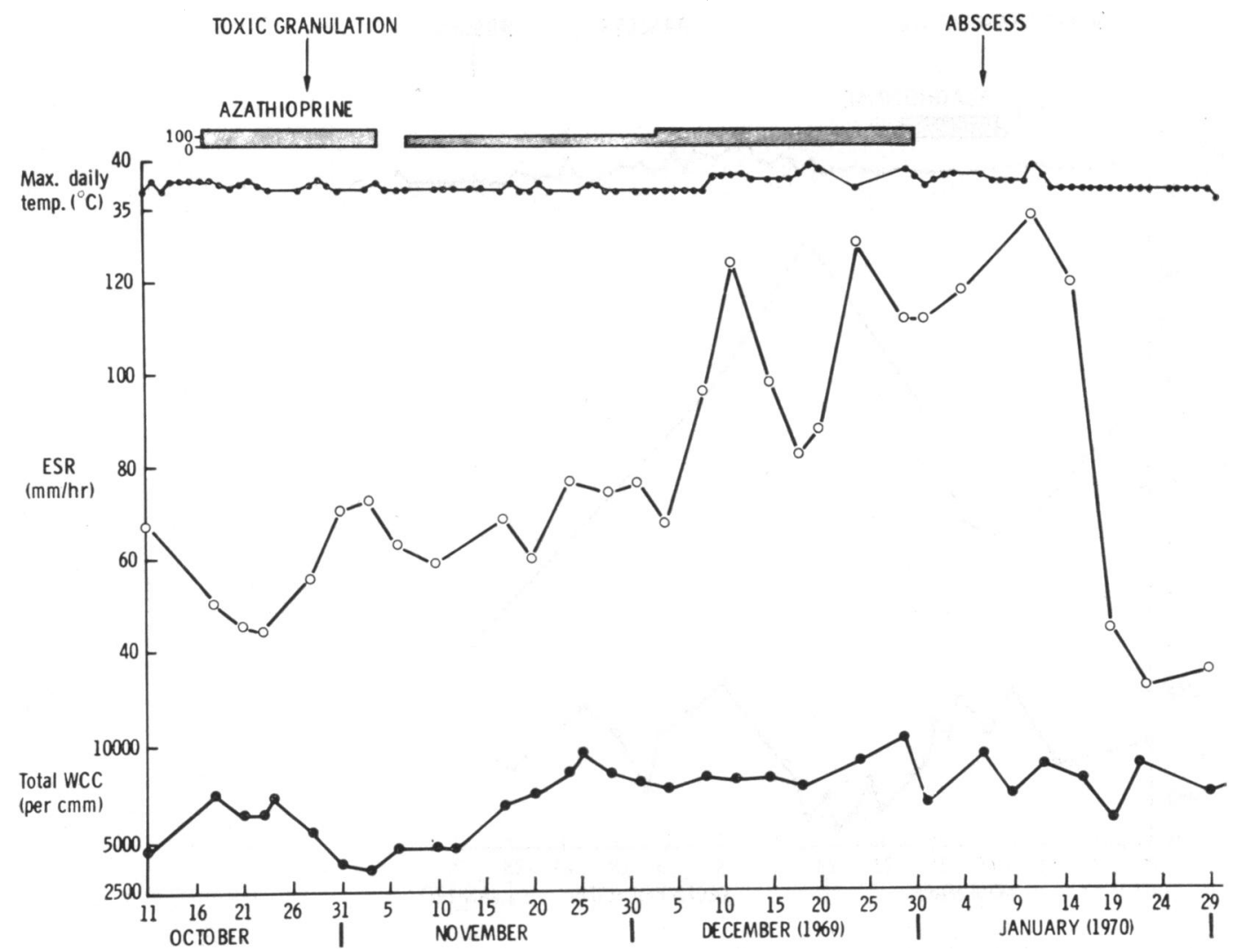

Fig. 1 First course of azathioprine.

26. On 30 December, he was noted to have psoas spasm, and impaired sensation in the distribution of the femoral branch of the left genito-femoral nerve. His fever had become slightly more marked with temperatures of up to $39.5^{\circ} \mathrm{C}$, and his ESR had risen to values between 80 and $125 \mathrm{~mm}$ in the first hour. On one occasion, the total white count was raised at $10300 \mathrm{cells} / \mathrm{cmm}$. In view of the possibility that he had developed an intraabdominal abscess, azathioprine was stopped. On 6 January an abscess started to point in the left groin, and on 12 January it started to discharge large amounts of pus which gave a moderate growth of $B$. coli and Strep. faecalis. Thereafter the patient became afebrile and his ESR rapidly fell towards normal. By the time of discharge on 18 February he felt much better in himself, the abscess had ceased to discharge, and his weight had increased to $50 \mathrm{~kg}$. He was afebrile and his ESR was 16. $\mathrm{mm}$ in the first hour. Following discharge he continued to feel well, and by July his weight was $67 \mathrm{~kg}$ on $5 \mathrm{mg}$ prednisolone daily.

He was readmitted on 29 October 1970 with diarrhoea and colicky abdominal pain. His weight had fallen again to $54 \mathrm{~kg}$. He had a fever of up to $37 \cdot 5^{\circ} \mathrm{C}$. His dose of prednisolone was raised to 30 mg daily on admission. This did not result in any clinical improvement, and his weight fell to $50 \mathrm{~kg}$. It was therefore decided to try the effect of a second course of azathioprine (Fig. 2). This was started on 12 November, at a dose of $200 \mathrm{mg}$ daily, this being reduced to $100 \mathrm{mg}$ daily 10 days later. Exactly the same sequence of events occurred as on the first admission. Toxic granulation of neutrophils was first noted on 14 November. His ESR rose to a maximum of $86 \mathrm{~mm}$ in the first hour on 30 November. By this time he had again developed pain in the left loin and hip, with paraesthesia in the distribution of the femoral branch of the left genito-femoral nerve. Azathioprine was therefore discontinued, and subsequently the total white cell count rose to a maximum of 11000 cells $/ \mathrm{cmm}$ and fever to $39 \cdot 5^{\circ} \mathrm{C}$. On 8 December the patient was started on streptomycin, paraaminosalicylic acid, and isoniazid on the outside possibility that the bowel lesion might be 


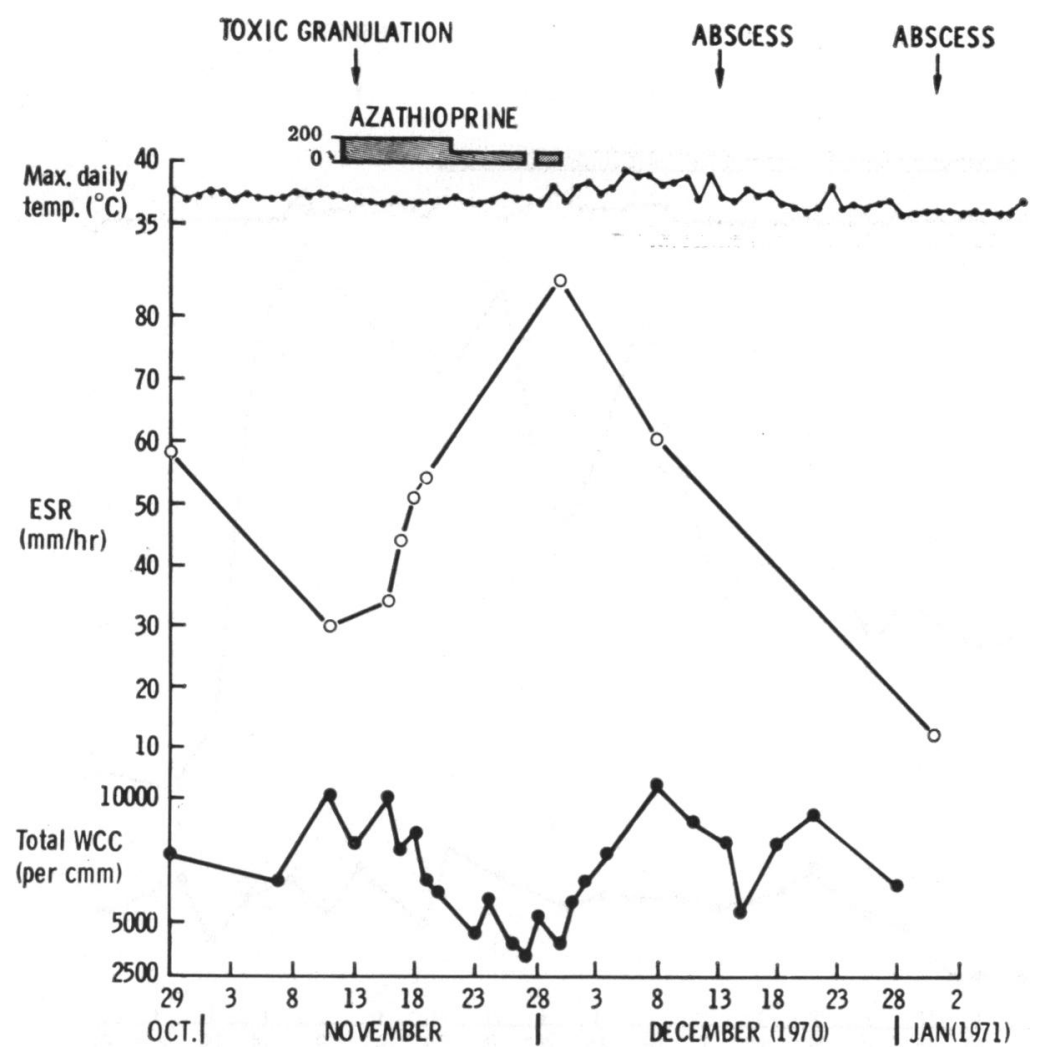

Fig. 2 Second course of azathioprine.

tuberculosis, and in view of the fact that his general condition was deteriorating. On 11 December an abscess started to point in the the left loin, and this was incised on December 13, releasing $200 \mathrm{ml}$ of pus which gave a heavy growth of $B$. coli. Direct examination, culture, and guinea-pig inoculation revealed no evidence of tubercle bacilli. A second abscess pointed in the left loin on 28 December, in exactly the same site as the abscess on his previous admission, and this was incised two days later. By the time of his discharge on 6 January, he felt well and was almost afebrile. His weight was rising, his ESR had fallen again to $12 \mathrm{~mm}$ in the first hour, and the abscesses had ceased to discharge. He was taking prednisolone $15 \mathrm{mg}$ daily. When seen again as an outpatient on 5 May, this improvement was sustained, and his weight had risen to $63 \mathrm{~kg}$ on $6 \mathrm{mg}$ prednisolone daily.

\section{Discussion}

There seems little doubt about the diagnosis of Crohn's disease in this patient, in view of the characteristic laparotomy and radiological findings, which included 'skip' lesions, a spontaneous ileocolic fistula, and the characteristic radiological appearances of 'cobblestoning' in the terminal ileum and 'spiking' in the transverse colon.

There is strong circumstantial evidence that azathioprine precipitated the development of an intraabdominal abscess on two separate occasions, at an interval of one year. On the first occasion the abscess pointed on the surface within 10 weeks, andon the second within four weeks of starting azathioprine. On both occasions, premonitory symptoms and signs appeared at an earlier stage than this. The patient had never previously had this complication, and on both occasions the abscess healed completely on stopping azathioprine.

Infective complications may be difficult to diagnose under these circumstances. As in our patient, fever may already be present as a feature of Crohn's disease, and azathioprine may prevent the development of a persistent polymorph leucocytosis. In retrospect, the earliest indication of a developing infection in our patient was the appearance of toxic granulation of neutrophils in the peripheral blood, 
accompanied by a progressively rising erythrocyte sedimentation rate. In view of this, it seems advisable in future to keep a close watch for these features in patients with Crohn's disease on treatment with azathioprine.

We thank Dr W. N. Mann for permission to publish clinical details of this patient.

\section{References}

Brooke, B. N., Hoffmann, D. C., and Swarbrick, E. T. (1969). Azathioprine for Crohn's disease. Lancet, 2, 612-614.

Brooke, B. N., Javett, S. L., and Davison, O. W. (1970). Further experience with azathioprine for Crohn's disease. Lancet, 2, 1050-1053.

Jones, F. A., Brown, P., Lennard-Jones, J. E., Jones, J. H., and Milton-Thompson, G. J. (1969). Azathioprine for Crohn's disease. Lancet, 2, 795. 